\title{
Decreased ability to acquire food of a captive deaf dolphin (Tursiops truncatus): Slower reaction times and lower success rates
}

\author{
Katherine A. Wright \\ This manuscript was prepared under the supervision of Dr. Elizabeth Boulding, \\ Department of Integrative Biology, College of Biological Sciences, University of Guelph
}

\begin{abstract}
Oceanic anthropogenic noise, such as naval sonar, can cause temporary hearing loss in cetaceans, but it is not known to what extent hearing loss affects cetacean behaviours such as feeding. This study used a captive deaf Atlantic bottlenose dolphin (Tursiops truncatus) to test the hypothesis that hearing loss would decrease a dolphin's ability to acquire food by preventing echolocation (using echoes to locate fish). Reaction time (time to acquire dropped fish) and success rate (percentage of successfully acquired fish) were measured for the deaf dolphin and for two dolphins with no known hearing disabilities at Dolphins Plus in Florida in May 2009. The deaf dolphin had a significantly slower mean reaction time and a significantly lower mean success rate than those of the two other dolphins. A hydrophone suggested that the deaf dolphin could not echolocate, and thus relied mainly on vision. The results illustrate that hearing loss can negatively affect a dolphin's ability to acquire food. Therefore, sources and effects of dolphin hearing loss require further investigation in order to provide targets for anthropogenic noise levels.
\end{abstract}

E cholocation is used by dolphins, like other cetaceans, to explore, navigate, socialize, and hunt fish, and it is possible that they use sound to stun or kill prey [1]. Echolocation is characterized by the emission of a series of acoustic pulses [2], which bounce off objects and return to the animal's inner ear. Oceanic anthropogenic noise can interfere with echolocation, affecting the daily activities and survival of cetaceans. Anthropogenic noise is caused by such things as naval sonar, engine noise from vessels, underwater explosions, and geophysical research [3], all of which produce sound frequencies that coincide with echolocation emitted and received by cetaceans $[4 ; 5]$. These frequencies can also interfere with natural sounds, hinder animal vocalizations used for communication in such means as socialization or reproduction, and cause stress or animal displacement $[3 ; 6 ; 7]$. These effects are observed in wild animals $[3 ; 6 ; 7]$, and can also be predicted by computer modeling. An acoustic exposure model [8] found that sound from whale watching boats could change Killer Whale (Orcinus orca) behaviour, could affect communication and may cause hearing loss. Cetaceans may attempt to combat environmental noise by vocalizing only when the noise has decreased or has disappeared, but it is unknown if this method is effective [5; 9]. Thus, for animals that rely heavily on sound, any acoustic disruption could be extremely disruptive and/or harmful.

The hypothesis that sonar from navy ships is causing at least temporary hearing loss in cetaceans, such as Atlantic bottlenose dolphins (Tursiops truncatus), has been supported and tested by a number of recent studies [e.g. 10;11; 12]. Mooney et al. $[11 ; 12]$ tested the effects of noise on dolphins (T. truncatus) using auditory evoked potentials, finding empirical proof that sonar can cause temporary hearing loss. Further support for this hypothesis includes numerous mass strandings that have occurred following naval activities in which ships deployed sonar [e.g. 13; 14]. Mass strandings generally result from events that have caused distress or disorientation [15] and stranding events that are considered related to sonar range worldwide, from places such as North Carolina [16], Hawaii [17], the Spanish Canary Islands [18], and the Bahamas [13]. In a report by Balcomb \& Claridge [13], autopsies of stranded cetaceans discovered hemorrhages in the inner ears, cranial spaces, and acoustic fats, which would have resulted from a significant acoustic or pressure event.

The effects of anthropogenic noise can extend beyond hearing loss to include disorientation, changes in diving and bubble production, and possibly decompression, among other physiological and behavioural changes [11]. Thus, as anthropogenic noise has increased in the oceans, cetacean noise-related mortalities may increase [11]. Recovery from temporary hearing threshold shifts at certain decibel levels has been reported in the beluga (Delphinaperus leucas) and dolphin ( $T$. truncatus), but it is unknown whether this phenomenon can be generalized to all cetaceans [19]. 
Research on cetacean hearing loss is still ongoing since deaf dolphins rarely exist in captivity [20], and an extensive literature search yielded no recorded cases of deaf dolphins in the wild even though deafness occurs. As a result, the few deaf dolphins currently living in captivity are important case studies in understanding cetacean hearing. An offshore Atlantic bottlenose dolphin at Dolphins Plus in Florida, named Castaway, is the second known captive deaf dolphin [21] and the subject of this research. She is deaf and, therefore, presumed unable to hear emitted echoes or other sounds, but it is unknown whether she can produce sound [22]. Testing her may help explain how hearing loss affects dolphin behaviour.

This study examined the effect of hearing loss on a dolphin's ability to acquire food by dropping fish $30 \mathrm{~cm}$ away from the subject's head. If echolocation cannot be utilized, then foraging success should theoretically decrease. Thus, it was hypothesized that hearing loss would decrease a dolphin's ability to acquire food because the dolphin cannot acquire relevant sounds via direct hearing or echolocation in order to locate fish. It was therefore predicted that the subject's reaction time would be slower and her success rate would be lower than those of dolphins with no known hearing disabilities. To verify that the deaf dolphin could not echolocate, a hydrophone was placed in the water. It was predicted that no vocalizations consistent with echolocation would be heard during her trials, but that they would be heard during the other dolphins' trials.

\section{METHODS}

\section{Study site}

This study was conducted at Dolphins Plus, a dolphin and marine mammal research and education facility, located in Key Largo, Florida (Figure 1). The facility consists of two dolphin enclosures, situated on opposite sides of a canal continuous with the Atlantic Ocean. The North side houses seven dolphins (T. truncatus) and the South side houses eight dolphins (T. truncatus) and one California sea lion (Zalophus californianus). The natural environment is characterized by the presence of shallow sea water, a floor of soft sedimentlimestone substrate, and small marine organisms. Water clarity, although variable, always permitted clear observations of feeding trials.

\section{Study subjects}

Castaway (Figure 2) is an adult, female offshore Atlantic bottlenose dolphin that was found stranded in November 2006 in Castaway Cove, Florida [22]. After rehabilitation and unsuccessful release attempts by Mote

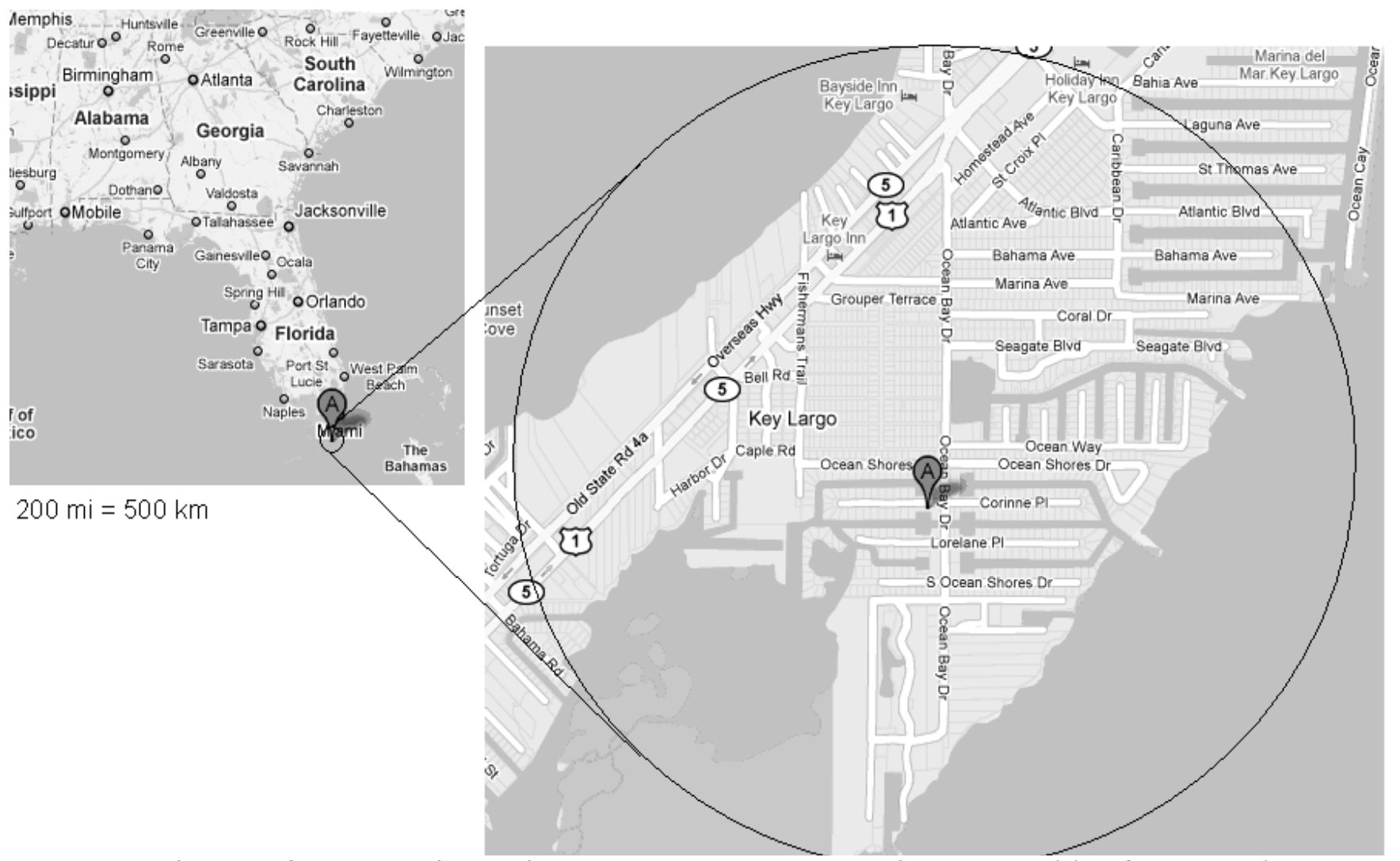

Figure 1: Map of Florida, USA, with magnification of Key Largo to illustrate the location of Dolphins Plus (A) on Google Maps (retrieved April 20, 2010; www.googlemaps.com) 
Marine Laboratory, two passive auditory tests conducted by Dr. David Mann confirmed her to be deaf, to have impairment in her right eye, and to exhibit signs of neurological deficiencies which were hypothesized to be the result of a stroke [22]. Once deemed non-releasable, she was transported to Dolphins Plus in July 2007 [22]. Castaway lives with six Atlantic bottlenose dolphins in the North enclosure and is estimated to be 35 years old [Dr. Stevens personal communication, May 2009].

Ding and Sarah (Figure 2) are adult, female Atlantic bottlenose dolphins, estimated at 32 and 26 years old respectively. Neither dolphin exhibits signs of hearing, visual or neurological deficits, and thus constituted the control group for this study. In addition to being of the same sex and same age group as Castaway, both were also once wild and also currently live in the North enclosure.

\section{Experiment 1: Reaction times and success rates with dead capelin}

All dolphins are fed a diet of herring, capelin, silversides and stickleback. Capelin was selected for the feeding trials because capelin is a universally predominant component of their diets. Herring, ideal because of its larger size, could not be used because of diet restrictions.

Fish presentation (left vs. right side) was determined using a random number table [23]. Both sides were used to account for side bias and possible impaired vision in Castaway's right eye.

During a training session, each dolphin participated in an individual response test to measure their respective ability to acquire food. A trainer at the dock dropped a series of dead capelin $30 \mathrm{~cm}$ from the dolphin's head to her left and right. The trainer wore sunglasses to avoid implications of eye contact. Preceding the presentation of fish, both of the trainer's hands were lifted from the bucket in an attempt to eliminate telegraphing.

A total of 40 trials were conducted at each of the 0930 $\mathrm{h}, 1400 \mathrm{~h}$ and $1600 \mathrm{~h}$ training sessions to decipher if reaction time varied at different times of day. There were eight trials (four to the left and four to the right) per session, for five of each of the three time sessions, to yield an overall total of 120 trials per subject. There were six different trainers, and each only worked with one dolphin subject. I was therefore unable to test directly for differences among trainers. Instead

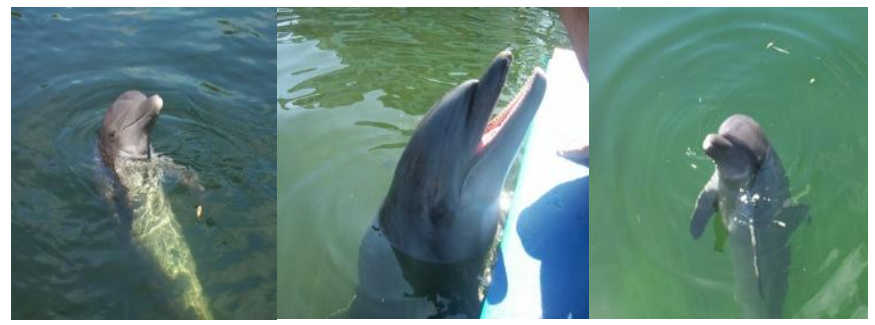

Figure 2 Photographs by author of Ding, Castaway, and Sarah (from left to right) at Dolphins Plus. Note that Castaway is now deceased (Dolphins Plus, 2010).
I tried to average out the differences among trainers by running an equal number of trials for the two trainers assigned to each dolphin. Trials ran throughout May 10-29, 2009 , depending on when the trainers were available and permitting weather conditions.

Three dependent variables were measured: reaction time, success rate, and hydrophone recordings. Firstly, reaction time (time from the fish release to the time the dolphin acquired the fish) was recorded using a stopwatch. A ruler was placed beside the trainer to measure the $30 \mathrm{~cm}$ distance. A reaction time test was completed prior to each session to monitor observer error. The average of two tests was used [24; 25]. Secondly, success rate was calculated as the percentage of trials in which the dolphin successfully acquired the capelin. The dolphin was considered unsuccessful if the live fish residing in the enclosure managed to acquire the capelin first. Thirdly, a hydrophone was placed in the water during the sessions to monitor any echolocation. Observations of feeding behavior were also recorded.

\section{Experiment 2: Reaction times and success rates with live shrimp}

For comparative purposes, the same systematic approach as outlined in Experiment 1 was followed using live shrimp for each dolphin. Again, reaction times were measured, success rates were calculated, and the hydrophone was used. Due to the high cost of shrimp and the challenge of keeping shrimp alive in storage, this experiment was done as a single cross-comparison (same day) with eight trials per dolphin during one $1600 \mathrm{~h}$ session.

\section{Statistical analysis}

Univariate analysis of variance (ANOVA) using two independent variables: "time of day" with three levels (0930 $\mathrm{h}, 1400 \mathrm{~h}$ and $1600 \mathrm{~h}$ ) and "dolphin" with three levels (Castaway, Sarah, and Ding) but with no interaction terms was performed separately for each of the dependent variables: capelin reaction times and capelin success rates. The success rates were transformed from percentages to arcsin values to meet ANOVA assumption of normality. If an independent categorical variable was significant in the ANOVA, then a Tukey post-hoc test was performed. A oneway analysis of variance (ANOVA) was performed on the dolphins' shrimp reaction times and a one-way Chi-square test was performed on the shrimp success rates because all the data was from only one session.

\section{RESULTS}

\section{Experiment 1: Reaction times and success rates with dead capelin}

Reaction times - In order from slowest to fastest: mean reaction times (in seconds \pm standard error) for Castaway, Sarah, and Ding were respectively $1.73 \pm 0.062 \mathrm{~s}, 1.33 \pm$ 
$0.028 \mathrm{~s}$, and $1.19 \pm 0.029 \mathrm{~s}$ (Figure 3). These values for capelin were significantly different $(p<0.0001$; Table 1$)$. Tukey post-hoc tests (Table 1) determined that Castaway had a significantly slower mean reaction time than both Ding and Sarah $(\mathrm{p}<0.0001)$. In addition, Sarah had a significantly slower mean reaction time than Ding $(\mathrm{p}=0.012)$.

Time of day also had a significant effect on reaction time $(\mathrm{p}=0.009$; Table 1$)$ with a faster average reaction time of the three dolphins at the $0930 \mathrm{~h}$ feeding session than the $1600 \mathrm{~h}(\mathrm{p}=0.013)$ and a faster average reaction time at the $1400 \mathrm{~h}$ session than the $1600 \mathrm{~h}$ session $(\mathrm{p}=0.013)$.

Success rates - In order from lowest to highest: mean success rates (in percentages \pm standard error) for Castaway, Ding, and Sarah were respectively $57 \pm 3 \%, 88 \pm 5 \%$, and 98 $\pm 3 \%$ (Figure 4). These values for capelin were significantly different ( $<<0.0001$; Table 2). Tukey post-hoc tests (Table 2) determined that Castaway had a significantly lower mean success rate in acquiring capelin before the resident fish than did Ding and Sarah $(\mathrm{p}<0.0001)$. In addition, Ding had a significantly lower mean success rate than Sarah $(\mathrm{p}=0.002)$.

When comparing success rates of fish presented on the left and right sides of each dolphin's head, all results were statistically insignificant. Castaway acquired $58 \%$ on her left side and $55 \%$ on her right. However, she showed little or no reaction for $10 \%$ of trials, of which $58 \%$ were on the right and $42 \%$ were on the left. Ding acquired $88 \%$ on her left and $83 \%$ on her right. Sarah acquired $97 \%$ on her left and $93 \%$ on her right.

Time of day did not have a significant influence on the success rates for the dolphins (Table 2).

\section{Experiment 2: Reaction times and success rates with live shrimp}

Reaction times -- In order from slowest to fastest: mean reaction times for Sarah, Castaway, and Ding were respectively $2.07 \pm 0.829 \mathrm{~s}, 1.99 \pm 0.120 \mathrm{~s}$, and $1.85 \pm 0.416 \mathrm{~s}$ (Figure 5), none of which were significantly different.

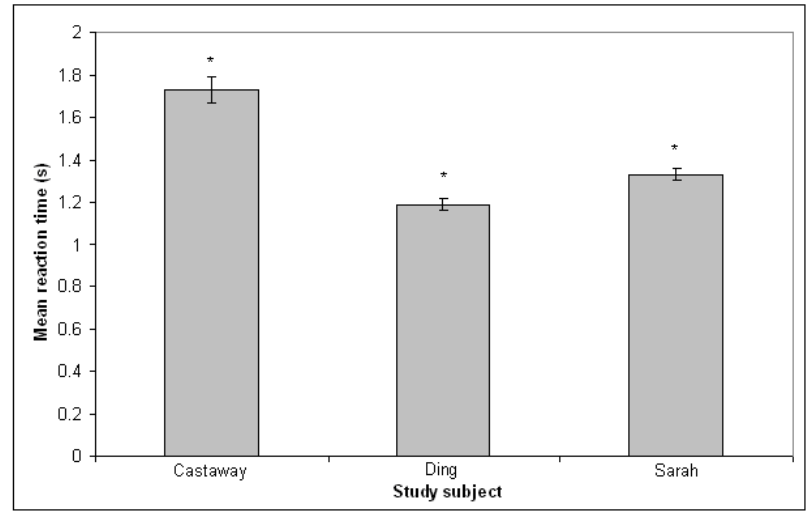

Figure 3 The mean reaction times (in seconds) for dead capelin trials for Castaway, Ding and Sarah ( $\pm 1 \mathrm{SE}$ ). Reaction time was recorded as the time from fish release to the time the dolphin acquired the fish. ${ }^{*}$ - denotes significant differences among the means for all three dolphins
Success rates - In order from lowest to highest: mean success rates for Castaway, Sarah, and Ding were respectively $25 \%, 75 \%$, and $88 \%$ (Figure 6), none of which were significantly different.

\section{Hydrophone results}

The hydrophone showed that no echolocation was emitted by Castaway in either the capelin or the shrimp trials; however, echolocation was emitted by Ding and Sarah.

\section{DiscuSSION}

The results of the dead capelin experiment supported the initial hypothesis that hearing loss decreases a dolphin's ability to acquire food by slowing reaction time and decreasing success rate. Castaway had a slower mean reaction time and lower mean success rate of collecting fish than Ding and Sarah. The hydrophone data indicated that Castaway did not utilize echolocation in any of the trials, whereas the other two control subjects did echolocate. Therefore, since the dolphin is unable to utilize echolocation to locate fish, it appears that hearing loss can make it more difficult to acquire food and thus deaf dolphins may be less efficient at foraging in the wild.

The live shrimp experiment did not support the initial hypothesis because there was no significant difference in reaction times among the three dolphins. In part, this may have been because the shrimp experiment included a low number of trials (eight) and fewer replicates result in inadequate statistical power to detect small differences. It was originally intended to use live fish, such as pin fish, for this second experiment because they resemble capelin in colour and size. Due to resources and cost, it was not possible to use live fish and thus live shrimp was used instead. All dolphins at Dolphins Plus, including Castaway,

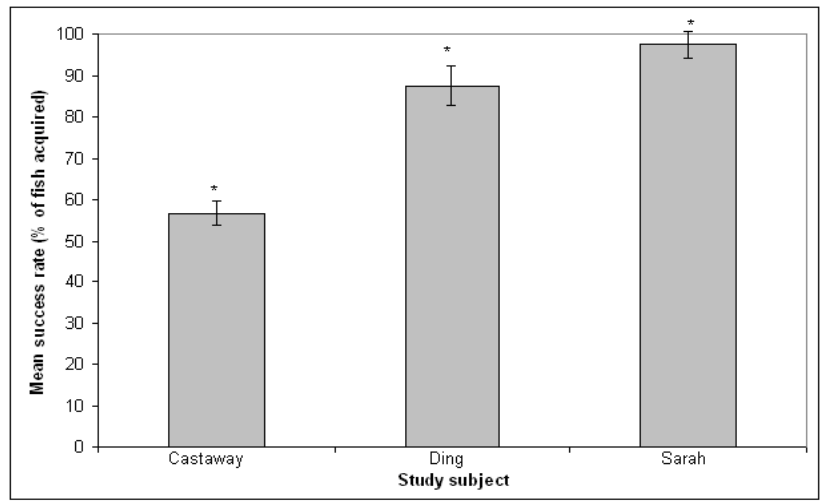

Figure 4: The mean success rates (in percentage of fish acquired) for dead capelin trials for Castaway, Ding and Sarah $( \pm 1 \mathrm{SE})$. Success rates were calculated as the percentage of trials in which the dolphin successfully acquired the capelin. * - denotes significant differences among the means for all three dolphins 
have been fed shrimp before, albeit infrequently. However, Castaway showed little interest in the shrimp and had a low success rate at capturing them. Her lack of interest could have occurred because shrimp are smaller than capelin and thus harder to see (assuming she relies on vision instead of echolocation), or because shrimp are not a regular dietary component. In comparison, the control dolphins, Ding and Sarah, were interested in the shrimp. It appeared as though Sarah played with the shrimp before consuming them, which could explain why her reaction time was the most variable. For all three dolphins, the shrimp reaction times were slower than those exhibited with dead capelin.

Unexpected significant differences were found between the two dolphins with no known hearing deficits, Ding and Sarah, for capelin reaction time and success rate. These differences could result from individual differences such as age or experience because, although both are adults, Ding is approximately 9 years older than Sarah. Furthermore, Ding had a faster mean reaction time but a lower mean success rate than Sarah, which is surprising because it would be logical for a dolphin with a faster reaction time to acquire more fish and thus be more successful. However, it is arguable that a higher success may depend less on the

Table 1: ANOVA and Tukey post-hoc test results for capelin reaction times compared for the three dolphins (1: Castaway, 2: Ding and 3: Sarah) and the three feeding sessions at different times of day (0930 h, $1400 \mathrm{~h}$ and $1600 \mathrm{~h}$ ).

\begin{tabular}{|l|r|r|r|r|}
\hline Source & df & Mean Square & \multicolumn{1}{|c|}{ F } & \multicolumn{1}{c|}{ Sig. } \\
\hline Model & 5 & 111.991 & 898.556 & $<0.001$ \\
Dolphin & 2 & 6.120 & 49.102 & $<0.001$ \\
Time of & 2 & .597 & 4.794 & 0.009 \\
day & & & & \\
Error & 284 & .125 & & \\
Total & 289 & & & \\
\hline
\end{tabular}

POST-HOC

\begin{tabular}{|ll|llr|}
\hline \begin{tabular}{ll|lr|}
$(\mathrm{I})$ \\
Dolphin
\end{tabular} & $\begin{array}{l}\text { (J) } \\
\text { Dolphin }\end{array}$ & $\begin{array}{c}\text { Mean } \\
\text { Difference } \\
(\mathrm{I}-\mathrm{J})\end{array}$ & $\begin{array}{l}\text { Std. } \\
\text { Error }\end{array}$ & Sig. \\
\hline 1 & 2 & $.5405^{\star}$ & .05516 & $<0.001$ \\
& 3 & $.4031^{*}$ & .05375 & $<0.001$ \\
2 & 1 & $-.5405^{\star}$ & .05516 & $<0.001$ \\
& 3 & $-.1373^{*}$ & .04761 & 0.012 \\
\hline
\end{tabular}

\begin{tabular}{|c|c|c|c|c|}
\hline $\begin{array}{l}\text { (I) Time } \\
\text { of day }\end{array}$ & $\begin{array}{l}\text { (J) Time } \\
\text { of day }\end{array}$ & $\begin{array}{c}\text { Mean } \\
\text { Difference } \\
(\mathrm{I}-\mathrm{J})\end{array}$ & $\begin{array}{l}\text { Std. } \\
\text { Error }\end{array}$ & Sig. \\
\hline $\begin{array}{r}9.30 \\
14.00\end{array}$ & $\begin{array}{l}14.00 \\
16.00 \\
9.30 \\
16.00\end{array}$ & $\begin{array}{l}.0002 \\
.1455^{\star} \\
-.0002 \\
.1452^{\star}\end{array}$ & $\begin{array}{l}.05056 \\
.05110 \\
.05056 \\
.05097\end{array}$ & $\begin{array}{l}1.000 \\
0.013 \\
1.000 \\
0.013\end{array}$ \\
\hline
\end{tabular}

animal's reaction time and more on their consistency. Testing on additional hearing dolphins would be ideal to eliminate high individual variability.

Unexpected significant differences were also found among the reaction times at different times of day, with reaction times being faster at the two earlier sessions $(0930 \mathrm{~h}$ and $1400 \mathrm{~h})$ than the later session $(1600 \mathrm{~h})$. This is logical because the dolphins receive a larger amount of fish at the $0930 \mathrm{~h}$ session as it is the first feed of the day and the dolphins are not fed overnight. However, while the reaction times varied, the success rates did not vary among the three sessions. Therefore, while the dolphins were generally faster earlier in the day, their overall success remained constant, which would be an important variable to consider for dolphins foraging in the wild.

According to Castaway's trainers and the observations from the tests conducted during her rehabilitation [22], her right eye showed some signs of visual impairment. However, the statistically insignificant results from this study of $58 \%$ capelin capture success on the left side and $55 \%$ on the right could alone suggest that either her visual impairment has improved, that she has learned to compensate for her sensory deficit, or that she may have improved her performance over the duration of the study through learning.

Learning may also contribute to Castaway's success rate increasing from an initial $38 \%$ to $57 \%$. It was originally questioned if the experiment would be too repetitive for the two dolphins with no known hearing disabilities, but their success rates were relatively consistent throughout the experiment to suggest otherwise. It is thought that a practice effect could possibly occur in the wild, as a deaf animal

Table 2: ANOVA and Tukey post-hoc test results for capelin success rates tested among the three dolphins (1: Castaway, 2: Ding and 3: Sarah) and for the three feeding sessions at different times of day (0930 h, $1400 \mathrm{~h}$ and $1600 \mathrm{~h})$.

\begin{tabular}{|l|rrrr|}
\hline Source & df & $\begin{array}{c}\text { Mean } \\
\text { Square }\end{array}$ & F & Sig. \\
\hline Model & 5 & 111.991 & 898. & $<0.0$ \\
& & & 556 & 01 \\
Dolphin & 2 & 10361.6 & 48.4 & $<0.0$ \\
& & 14 & 65 & 01 \\
Time of day & 3 & 200.613 & .938 & .431 \\
Error & 39 & 213.797 & & \\
Total & 45 & & & \\
\hline
\end{tabular}

\begin{tabular}{|c|c|c|}
\hline (I) Dolphin & (J) Dolphin & Sig. \\
\hline $\begin{array}{l}1 \\
2\end{array}$ & $\begin{array}{l}2 \\
3 \\
1 \\
3\end{array}$ & $\begin{array}{r}<0.001 \\
<0.001 \\
<0.001 \\
0.002\end{array}$ \\
\hline
\end{tabular}




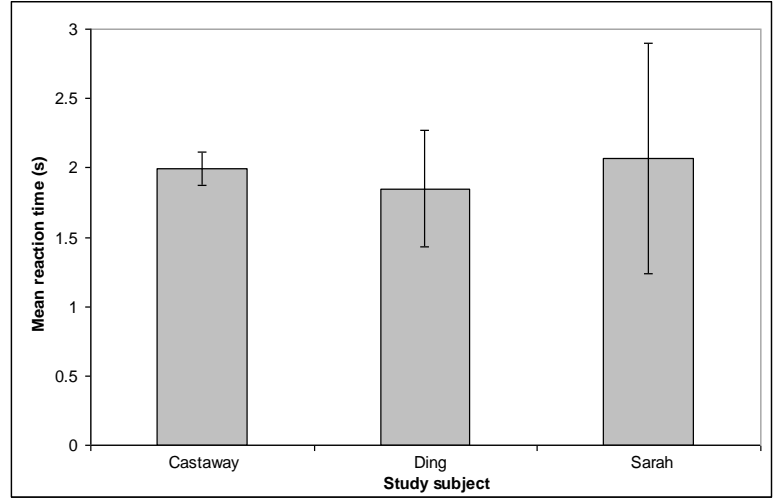

Figure 5: The mean reaction times (in seconds) for live shrimp trials for Castaway, Ding and Sarah ( $\pm 1 \mathrm{SE})$

learns to cope with the loss of a major sensory mechanism. Whether a deaf dolphin could survive in the wild is another question entirely. Another deaf dolphin, which resides in California and is referred to as Dolphin SIB, was predicted to be able to survive and forage effectively by using other senses and by learning from other dolphins [20]. However, even with potential aid from pod members, there are many obstacles for survival; as avoidance of fishing nets is only one of many. It is possible to visually detect nets, but that depends on water clarity and depth, as well as on the visual versus echolocation ability of a species. Especially with numerous nets now designed with devices that emit acoustic frequencies to signal their presence to marine animals [26; 27], avoiding entanglement may be easier by using echolocation and therefore a deafened cetacean may be at a large disadvantage.

The naturalistic setting of Dolphins Plus is advantageous because the interference of resident fish and sea birds represented competition for food in this particular study. An artificial setting with no fish or birds would eliminate competition, and thus might provide a different perspective on the effect of hearing loss on a dolphin's ability to acquire food.

This study intended to test how hearing loss affects the ability to acquire food, but as the experiment continued, it was highly suspected that vision was also involved, especially for Castaway. This raises the question of if hearing loss can be compensated by another sense such as vision. If it cannot be compensated, then feeding behaviour in the wild may still be affected. Although this experimental feeding method can assess if a deaf dolphin can use vision to cope with having lost a major sense, cupping the eyes and releasing fish underwater could better isolate for the effect of hearing. However, neither procedure can prevent dolphins from tactilely sensing water vibrations from the fish which may be possible since cetaceans can tactilely detect water movement over their bodies due to dermal receptors [28]. In addition, hair follicles may be involved since it is speculated that the vibrissae of freshwater river dolphins are used to

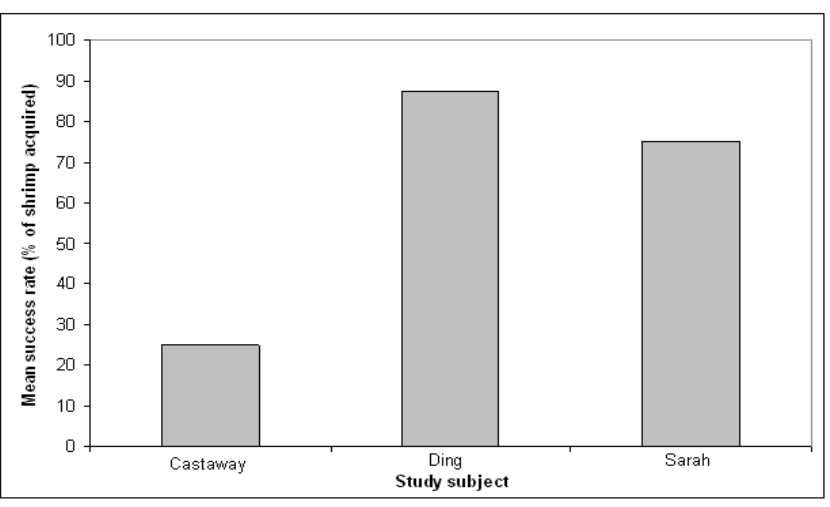

Figure 6: The mean success rates for live shrimp trials (in percentage of shrimp acquired) for Castaway, Ding and Sarah

follow water disturbances of prey which are generally difficult to visually locate due to the poor clarity of the river waters $[29 ; 30]$. Unfortunately, there was also no possible method to isolate for the effect of Castaway's neurological deficiencies that, in addition to her deafness, were believed to be caused by a stroke.

This study used one deaf dolphin and two with no known hearing deficits. A larger sample size would allow replication; however this is difficult because few deaf dolphins exist in captivity. Dolphin SIB [20] appears to have similar logging behaviour and social skills as Castaway; however the main difference between these dolphins is that Dolphin SIB is not visually impaired. For future studies, comparing reaction times and success rates between one dolphin who is only hearing impaired and one who is hearing and visually impaired could provide insight on the importance of hearing versus vision during feeding.

Cetaceans can lose hearing abilities, but more research is needed to determine how hearing loss affects cetaceans long-term. As this study tested feeding behaviour, future studies could investigate hearing loss in activities beyond feeding such as social structure. Dolphins are very social animals; it would be worth investigating how a deaf dolphin would be affected socially within the pod and if a deaf dolphin would even be capable of finding a mate or raising a calf. Castaway gave birth to a calf while in rehabilitation, but the calf died at four days old [31]. However, the death of the calf cannot fully be attributed to Castaway's disabilities because the survival rate of calves is low, especially for calves in their first year [32]. Cetacean hearing loss is an area not fully understood, and it is expected that hearing loss affects many cetacean daily activities, of which feeding, social structure, and mating are only a few examples.

This is the first study to show that hearing loss decreases an Atlantic bottlenose dolphin's ability to acquire food by slowing reaction time and decreasing success rate. If hearing loss does affect overall survival, then multiple sources of hearing loss need to be considered. This study 
focused on anthropogenic noise, but since it was suspected that Castaway's deafness occurred due to a stroke, more research on that subject would also be beneficial. In regards to noise levels, "safe" decibel levels vary among species; but it must be determined to what extent these levels are affected by other anthropogenic noise and if cetaceans have become more sensitive over the years than the "safe" $180 \mathrm{~dB}$ limit declared by US Navy $[11 ; 33]$. Noise levels produced by such means as naval sonar and vessel engines should be kept within a range that will not be harmful to cetaceans, and since oceanic noise levels have increased [9], this "safe" range may require adjusting. Therefore, investigating sonar and other potential sources responsible for causing temporary and permanent hearing loss, as well as their effects on cetaceans, could further our understanding of these animals and lead to better-informed conservation measures, especially those in regards to anthropogenic noise.

\section{CONCLUSION}

Hearing loss greatly affects marine mammals that rely heavily on echolocation. Sound plays an important role in their daily activities and, as shown in this study, hearing loss negatively impacts a dolphin's ability to acquire food. A slower reaction time and lower success rate in feeding on dead capelin resulted in less food acquired by a deaf dolphin relative to two control dolphins with no known hearing disabilities. These results suggest that permitted levels of oceanic anthropogenic noise need to be further examined to ensure that they do not cause, or continue to cause, temporary or permanent hearing loss in marine mammals.

\section{ACKNOWLEDGEMENTS}

A sincere thank you goes to all the staff at Dolphins Plus for their expertise and assistance in performing the experiment, but especially to the trainers of the three dolphin subjects. Special thanks to internship coordinator Meghan Weinpress, mentor Sarah Sayre, and advisor Dr. Jill Richardson. Also a very special thank you goes to my onsite advisor Holli Byerly. Thank you to Kelly McNichols and Karen Rickards at the University of Guelph for reading the manuscript and to Dr. Karl Cottenie for his advice. Another very special thank you goes to my faculty advisor Dr. Elizabeth Boulding for her much appreciated assistance throughout the project process.

\section{REFERENCES}

1. Marten, K., Herzing, D., Poole, M. \& Newman Allman, K. (2001). The acoustic predation hypothesis: linking underwater observations and recordings during Odontocete predation and observing the effects of loud impulsive sounds on fish. Aquatic Mammals, 27(1), 5666.

2. Reeves, R. R, Stewart, B. S., Clapham, P. J. \& Powell, J. A. (2002). Guide to marine mammals of the world (1st ed., pp. 18, 506). New York: Alfred A. Knopf, Inc.

3. Weilgart, L. S. (2007). The impacts of anthropogenic ocean noise on cetaceans and implications for management. Canadian Journal of Zoology, 85, 10911116.

4. Croll, D. A., Clark, C. W., Calambokidis, J., Ellison, W. T. \& Tershy, B. R. (2001). Effect of anthropogenic low-frequency noise on the foraging ecology of Balaenoptera whales. Animal Conservation, 4(1), 1327.

5. Tyack, P. L. (2008). Implications for marine mammals of large-scale changes in the marine acoustic environment. Journal of Mammalogy, 89(3), 549-558.

6. Myrberg, A. A. J. (1990). The effects of man-made noise on the behavior of marine animals. Environment International, 16, 575-586.

7. O'Shea, T. J. \& O'Dell, D. K. (2008). Large-scale marine ecosystem change and the conservation of marine mammals. Journal of Mammalogy, 89(3), 529533.

8. Erbe, C. (2002). Underwater noise of whale-watching boats and potential effects on killer whales (Orcinus orca), based on an acoustic impact model. Marine Mammal Science, 18(2), 394-418.

9. Nowacek, D. P., Thorne, L. H., Johnston, D. W. \& Tyack, P. L. (2007). Responses of cetaceans to anthropogenic noise. Mammal Review, 37(2), 81-115.

10. Parsons, E. C. M., Dolman, S. J., Wright, A. J., Rose, N. A. \& Burns, W. C. G. (2008). Navy sonar and cetaceans: Just how much does the gun need to smoke before we act? Marine Pollution Bulletin, 56(7), 12481257.

11. Mooney, T. A., Nachtigall, P. E. \& Vlachos, S. (2009a). Sonar-induced temporary hearing loss in dolphins. Biology Letters, 458(7240), 807-838.

12. Mooney, T. A., Nachtigall, P. E., Breese, M., Vlachos, S. \& Au, W. W. L. (2009b). Predicting temporary threshold shifts in a bottlenose dolphin (Tursiops truncatus): The effects of noise level and duration. Journal of the Acoustical Society of America, 125(3), 1816-1826.

13. Balcomb, K. C. \& Claridge, D. E. (2001). A mass stranding of cetaceans caused by naval sonar in the Bahamas. Bahamas Journal of Science, 8(2), 2-12.

14. Acoustic Ecology Institute, (2005). Excerpts from the Science Committee Report, Annex K: Report of the Standing Working Group on Environmental Concerns. Proceedings of the International Whaling Commission meetings 2005.

15. Royal Society for the Prevention of Cruelty to Animals (RSPCA). (1992). Stranded whales, dolphins and 
porpoises: A first aid guide ( $2^{\text {nd }}$ ed., pp. 6-7). Horsham, RSPCA.

16. Kaufman, M. (2004, August 1). Sonar used before whales hit shore. Washington Post, A3.

17. Kaufman, M. (2005, January 28). Whale stranding in N.C. followed navy sonar use. Washington Post, A3.

18. Fernández, A., Edwards, J. F., Rodríguez, F., Espinosa de los Monteros, A., Herráez, P., Castro, P., Jaber, J. R., Martín, V. \& Arbelo, M. (2005). "Gas and fat embolic syndrome" involving a mass stranding of beaked whales (family Ziphiidae) exposed to anthropogenic sonar signals. Veterinary Pathology, 42, 446-457.

19. Nachtigall, P. E., Pawloski, J. L. \& Au, W. W. L. (2003). Temporary threshold shifts and recovery following noise exposure in the Atlantic bottlenosed dolphin (Tursiops truncates). Journal of Acoustical Society of America, 113(6), 3425-3429.

20. Ridgway, S. H. \& Carder, D. A. (1996). Hearing deficits measured in some Tursiops truncates, and discovery of a deaf/mute dolphin. Journal of Acoustical Society of America, 101(1), 590-593.

21. Dolphins Plus. (2010). Dolphin News. Retrieved from http://www.dolphinsplus.com/dolphin-news.htm.

22. Sayre, S., Wright, M., Cooper, N. \& Richardson, J. (2007a). Contacting “Castaway”: training a wild, deaf, offshore Atlantic bottlenose dolphin (Tursiops truncates). Proceedings from $35^{\text {th }}$ Annual IMATA Conference, Abstract: 31. Indianapolis.

23. Sungar, E. A., (2009). Table of Random Numbers. Retrieved 5 May 2009, from http://www.morris.umn.edu/ sungurea/introstat/public/i nstruction/ranbox/randomnumbers.

24. Allen, J. (2002). Reaction time test. Retrieved 5 May 2009, from http://getyourwebsitehere.com/jswb/rttest01.html.

25. Human Benchmark, (2009). Reaction test. Retrieved 5 May 2009, from http://www.humanbenchmark.com/tests/reactiontime/in dex.php.

26. Stone, G., Kraus, S., Hutt, A., Martin, S., Yoshinaga, A. \& Joy, L. (1997). Reducing by-catch: Can acoustic pingers keep Hector's dolphins out of fishing nets? Marine Technology Society Journal, 31(2), 3-7.

27. Barlow, J. \& Cameron, G. A. (2003). Field experiments show that acoustic pingers reduce marine mammal bycatch in the California drift gill net fishery. Marine Mammal Science, 19(2), 265-283.

28. Thomas, J. A. \& Kastelein, R. A. (1991). Sensory abilities of cetaceans: Laboratory and field evidence $\left(1^{\text {st }}\right.$ ed. pp. 163-166). New York: Springer.

29. Mauck, B., Eysel, U. \& Dehnhardt, G. (2000). Selective heating of vibrissal follicles in seals (Phoca vitulina) and dolphins (Sotalia fluviatilis guianesis.) Journal of Experimental Biology, 203, 2125-2131.

30. Reep, R. L., Stoll, M. L., Marshall, C. D., Homer, B. L. \& Samuelson, D. A. (2001). Microanatomy of facial vibrissae in the Florida Manatee: The basis for specialized sensory function and oripulation. Brain, Behaviour and Evolution, 58, 1-14.

31. Marine Mammal Conservancy, (2007). Rescue \& Rehab. Retrieved 7 March 2009, from http://www.marinemammalconservancy.org/rescue_and _rehab_strandings_castaway.html.

32. Mann, J. J., Connor, R. C., Barre, L. M. \& Heithaus, M. R. (2000). Female reproductive success in bottlenose dolphins (Tursiops sp.): life history, habitat, provisioning, and group-size effects. Behavioral Ecology, 11(2), 210-219.

33. Surveillance Towed Array Sensor System Low Frequency Active (SURTASS LFA). (2010). Selection of $180 \mathrm{~dB}$ as the upper reference point in the risk continuum for SURTASS LFA sonar signals. Retrieved 10 Sept. 2010, from http://www.surtass-lfaeis.com/docs/180dBCriteria.pdf. 